\title{
MISPLACED EMPHASES IN WARS ON POVERTY
}

\author{
SIMON ROTTENBERG*
}

The current preoccupation with poverty and the construction of policies to alleviate it is only a recent link in a long historical chain. The beginning is shrouded in antiquity but it is known, staying with the Anglo-Saxon world, that in the Middle Ages there were associations of begging friars, monastic provision of food and shelter for poor wanderers, and networks of hospitals for lepers, the diseased poor, distressed women big with child, and for the infirm and impotent poor. The Church also organized private charity and the guilds operated on the principle of mutual self-help. When the medieval institutions disappeared, they were replaced by the Elizabethan Poor Law which assigned parochial responsibility for the care of the poor, and by a supplementary system of private philanthropy.

The condition of life of the people in this country was so commonly bad in its early years that not much explicit attention was given to the poor, but the New York Society for the Prevention of Pauperism had already published its Second Annual Report in $18 \mathrm{rg}$, and "sanitary reformers" were active by the I840s. Many of the public policies now being executed under the descriptive euphemism "economic opportunity programs" have antecedents that are old in American experience.

The poor are defined in terms of the quantity of real goods and services they consume, relative to some standard. This standard for distinguishing the poor from others in society has been constructed in a number of different ways. Eugene Smolensky says there are two sets: those that aim to "determine the number or proportion of the population living at, or below, some insufficient welfare level (minimum decency estimates)" and those concerned with "the way in which the total available supply of goods and services is distributed between the rich and the poor (distribution estimates)."

Minimum decency estimates are produced by the design of some basket of commodities and services which are considered to be the minimal requirements for "subsistence," "comfort," or "decency." The basket is then priced in the marketplace and this yields a dollar-number which can be used, by observing the incomes of all families, to differentiate the poor from others. It is such a procedure as this, employed by the Social Security Administration, that produced the numbers $\$ 3,000$ for a family and $\$ 1,500$ for an individual living alone (sometimes $\$ 3,130$ for nonfarm

*A.B. 1939, George Washington University; A.M. 1948, Ph.D. 1950, Harvard University. Professor of Economics, Duke University. Contributor of articles and book reviews to professional journals.

${ }^{3}$ Smolensky, The Past and Present Poor, in Task Force on Economic Growth and Opporruniry, Chansber of Commerce of the United States, The Concept of Poverty [hereinafter cited as The Concept of Poverty] 36 (1965). 
families of four, $\$ 2,190$ for farm families of four, $\$ 1,540$ for nonfarm individuals, and $\$ 1,080$ for farm individuals) that are used in current discussion to define the margin of poverty.

Distribution estimates of poverty can be made only if income is unequally distributed. They may define the poor as those in the lowest twenty per cent, say, of all families ranked by income, and proceed one further step to define the extent of poverty by observing the distance between the sum of the incomes of those families and the number which is twenty per cent of the incomes of all families. Victor Fuchs offers a variant of the same set. He defines the poor as those families with incomes less than one half of that of the median family.

The standard that is used will determine the number of the poor. Fuchs' procedure says that poor families were a constant one-fifth fraction of all families in all years 1947 through 1960 , while the $\$ 3,000$ standard (adjusted for differences in prices of each year from those of 1959) says that the poor were thirty-four per cent of all families in 1947 and twenty-two per cent of them in 1960 . It is significant that one measure showed the quantity of poverty to be stable over time and the other showed it to shrink. ${ }^{3}$

It can be seen that some distribution estimates will say there is poverty even if we are all as rich as Croesus, and others will say it if we are all as rich as Croesus but only if income is sufficiently unequally distributed.

The words "comfort" and "decency" in the minimum-comfort estimates have the property of temporal one-way elasticity. They always expand and never contract, even when adjusted for changes in prices. And at any given moment of time fair men will differ over the content of the appropriate minimal basket. G. J. Stigler calculated, for example, that a minimum-cost diet containing all the nutrients recommended by the National Research Council for a "moderately active man" would have cost in 1939 , for a full year, about $\$ 40 .{ }^{4}$ This was only one-third to one-half of the costs of food intended to serve the same object in the same year that were calculated by others, including statisticians and dieticians of the U.S. Department of Agriculture. The cost differences derive, of course, from differences in the composition of the baskets. It cost, in 1939, twenty-one times as much to get as much protein from chuck roast as from dried navy beans. If "decency" requires the appearance of chuck roast in the diet, the income necessary to classify a family as outside the poverty line is higher; if navy beans suffice, it is lower.

How well do the American poor live? H. P. Miller reports ${ }^{5}$ that of families with incomes of less than $\$ 3,000$ per year,

\footnotetext{
${ }^{2}$ Fuchs, Toward a Theory of Poverty, in The Concept of Poverty 74.

'Id. at 75 .

'Stigler, The Cost of Subsistence, 27 J. FarM Econ. 3 II (I945).

${ }^{8}$ Miller, Major Elements of a Research Program for the Study of Poverty, in ThE ConcEpt of POVERTY 122.
} 
79 per cent own a television set

$5^{I}$ per cent own a television set and a telephone

73 per cent own a washing machine

rg per cent own a home freezer

65 per cent have a dwelling unit that is not dilapidated and has hot running

water and a toilet and a bath for their exclusive use

I4 per cent bought a car last year.

The conditions of life of these poor can, with some interest, be compared with those of the London poor at the beginning of the nineteenth century: ${ }^{8}$

Persons of the lowest class do not put clean sheets on their beds three times a year; ... curtains ... are never cleaned but suffered to continue in the same state until they fall to pieces; . . . from three to eight individuals of different ages often sleep in the same bed, there being in general one room and one bed for each family. ... The room occupied is either a deep cellar, almost inaccessible to light, and admitting of no change of air; or a garret with a low roof and small windows, the passage of which is close, kept dark, and filled not only with bad air, but with putrid excremental efluvia from a vault at the bottom of the staircase. . . . Some unsavoury victuals are from time to time cooked. ... The apartments are clogged ... [and] favour the accumulation of heterogeneous filth.

Dr. Southwood Smith wrote of the neighborhoods of habitation of the London poor in $1839:^{7}$

While systematic efforts on a large scale have been made to widen the streets, to remove obstructions to the circulation of free currents of air, to extend and perfect the drainage and sewerage, and to prevent the accumulation of putrefying vegetable and animal substances in the places in which the wealthier classes reside, nothing whatever has been done to improve the condition of the districts inhabited by the poor. . . . Such is the filthy, close and crowded state of the houses, and the poisonous condition of the localities ... from the total want of drainage, and the masses of putrefying matter of all sorts which are allowed to remain and accumulate indefinitely .... In these pestilential places the industrious poor are obliged to take up their abode; they have no choice. ... The present returns ... show that out of 77,000 persons (in- and out-door paupers) 14,000 have been attacked with fever ... and that nearly $I, 300$ have died.

Other reports of the period were said to show that the slums of London "were in no way exceptional; they were indeed surpassed in horror by the courts of Glasgow, the cellar dwellings of Manchester, and the common lodging houses of Birmingham."8 Rowntree's investigators found, in the late r930s in York, slum housing of which the following is not unrepresentative:

\footnotetext{
'Robert Willan, Reports on the Diseases in London 255 (1801), quoted in M. Dorothy George, LoNdON LIFE IN THE EIGHTEENTH CENTURY 86 (I95I).

'Sir John Simon, English Sanitary Institutions $183-84$ (1839), quoted in Gildert Siater, Poverty aNd the State 108 (I930).

${ }^{8}$ SLATER, Op. cit. supra note 7 , at 110 .

- B. Seebohm Rowntree, Poverty and Progress 253 (1941).
} 
The house (occupied by a family of four) shares a common yard with ten other houses. It shares a w.c. with another house and a water tap with two others. There is no water or sink in the house. The house is verminous.... Much of the brickwork is perished. The roof is sagged and defective. The kitchen floor has sunk and is broken. ... The plaster has perished owing to ground dampness. The woodwork is ill-fitting and rotted. The pantry has no external light or ventilation.

It is clear that the poor were once more easily identified than now. The discussion in the recent literature over the proper definition of poverty is perhaps evidence that tortured processes must be resorted to if people who are really quite affluent, even in a relatively short historical context, are to be called "poor." Assume, however, that definitions that have come to be accepted in political discourse are sensible. How many poor are there and what are their qualities? ${ }^{10}$

\begin{tabular}{|c|c|c|c|}
\hline \multicolumn{4}{|c|}{ Persons in Poverty Status in ig63 (Milions) } \\
\hline \multirow[b]{2}{*}{ Type of unit } & \multirow{2}{*}{$\begin{array}{l}\text { Total U.S. } \\
\text { Population }\end{array}$} & \multicolumn{2}{|c|}{ Below the Poverty Level } \\
\hline & & Number & Percent \\
\hline Total number of persons & 187.2 & 34.6 & 18 \\
\hline Farm & 12.6 & 3.2 & 25 \\
\hline Nonfarm & $\mathrm{x} 74.6$ & $3 \mathrm{I} \cdot 4$ & 18 \\
\hline Unrelated individuals & II.2 & 4.9 & 44 \\
\hline Members of family units & $I_{7} 6.0$ & 29.7 & I7 \\
\hline Children under 18 & 68.8 & 15.0 & 22 \\
\hline
\end{tabular}

About thirty million people in 7.2 million families and almost five million unrelated individuals-in all, 34.6 million persons, or eighteen per cent of the whole population of the country-were in a state of poverty in $1963^{11}$ If one examines the characteristics of poor families, it is found that the incidence of poverty falls especially heavily upon farm families, nonwhite families, families whose head is either relatively young or relatively old, families with a female head, families with large numbers of children, families without income-earners, and families whose head was unskilled or who did not work during the year or worked only part time. ${ }^{12}$ Many of these are not simply accidentally correlative characteristics but are rather causally associated with low income. On the average, farmers, women, young people and old, unskilled workers, the unemployed and part time workers are lowincome earners. They are, therefore, more likely to be found among the poor than others. It follows that whatever tends to increase the incidence of these

\footnotetext{
10 The numbers that follow are taken or derived from Orshansky, Counting the Poor, Soc. Sec. Bull., Jan. 1965, p. 3 .

12 The President reported in January 1966 that the quantity of poverty, measured in numbers of poor people, had been reduced to 17 per cent of the whole population or 32 million persons. N.Y. Times, Jan. 28 , 1966, p. 14 , col. 3 .

12 "Heavy incidence" does not necessarily mean that families with the indicated characteristics are a large fraction of all poor families, but rather that of all families with these characteristics, a large fraction of them is poor.
} 
characteristics in the whole population will also tend to enlarge the number of the poor. Similarly, whatever tends to cause low income to be associated with these characteristics will also tend to enlarge the number of the poor.

An examination of various facets of public policy in the United States will show that some fraction of poverty which we encounter among the people is, in fact, produced by government. Those who promote these policies do not, of course, intend nor desire that they shall have these effects; indeed, some of them are thought to promote progress and ameliorate poverty. Their enactment and execution is a tribute to the power in the world of the naïve cliché. Only some of these poverty-producing policies will be discussed.

I. The Fair Labor Standards Act of $193^{88^{13}}$ establishes a legal minimum hourly wage for those employed in a large sector of the economy. This minimum is probably irrelevant for most workers who, even in the absence of the law, would be paid more than the law requires. It is not irrelevant, however, for those in the lowest-skill classes. The law requires that wages paid in some unskilled occupations be higher than the level at which the market would set them. The consequence is that a smaller number of workers is employed in those occupations than would be if there were no minimum wage law, because firms seeking lowest-cost resource combinations are given an incentive to use substitutes for now more expensive unskilled labor. Workers who would have been employed in those occupations but who are kept from them by the law's higher-wage standards are either forced into unemployment or enter occupations that are not covered by the law. In these occupations they are worse off than they would have been (it is for them a secondbest option which they take only because the law shuts off preferred opportunities) and, in addition, larger numbers entering these occupations-where the wage paid is already less than the legal minimum-depress wages there for all, including incumbents in the occupations. ${ }^{14}$

2. The National Labor Relations Act $^{15}$ establishes procedures to determine whether workers in a "bargaining unit" desire to be represented by a trade union and, if their decision is affirmative, requires that firms negotiate with the relevant union the terms of employment. The act promotes trade unionism. If a union is effective (i.e., if it is not innocuous), the rate of wages in the occupations to which it has reference will be higher than the rate that would have prevailed in the absence of unionism. This is equivalent to saying, definitionally, that the union has and exercises monopoly power. Such a higher wage rate has the same adverse employment consequences and the same depressant effects upon wages paid in other occupations as do minimum wage laws. Some workers (those who are employed at the higher rates) are privileged at the cost of other workers. Unions often ad-

\footnotetext{
${ }^{12}$ 51 Stat. 1060, as amended, 29 U.S.C. $\$ \$ 20 \mathrm{I}-\mathrm{rg}$ (1964).

1s Stigler, The Economics of Minimum Wage Legislation, 36 AM. Econ. Rev. 358 (1946).

${ }^{2 t} 49$ Stat. 449 (1935), as amended, 29 U.S.C. $\$ \$$ I5I-68 (I964).
} 
minister rationing instruments or rules to distribute the smaller quantity of employment offered among workers who aspire to them. Sometimes the rationing rule implies an equal sharing of adversity and this finds expression in the form of a short work week for all. Short work weeks have, of course, the outcome that output is diminished and smaller output means more poverty. Sometimes the rule involves unequal sharing of adversity, as when some are excluded entirely. This may take the form of excluding some from the union and, therefore, excluding them from occupations for which entry into the union is a condition for entry into the occupation. When this tactic is employed, not infrequently it is Negroes who are excluded. Or the rationing rule may be some seniority system which distributes privilege in proportion to longevity of service with the firm. Here, too, it is Negroes, who are the late entrants into the lower ranks of an occupation, who are disadvantaged.

3. Farming in the United States is a declining occupation, measured by the relative numbers of persons employed in it. The outmigration from farming is responsive to superior earnings in other sectors, and the relatively low earnings in agriculture can be taken as a proxy for relatively low productivity of employment in agriculture. Output for the economy as a whole would be larger if fewer persons were employed in agriculture and more in other sectors. At least since the middle of the 1930s, public policy has subsidized farmers at the expense of the rest of the community and this has had the effect of diminishing the rate of outmigration from agriculture. Whatever induces people to remain in agriculture will have adverse output consequences and, thus, will tend to enlarge the quantity of poverty.

4. The Social Security Act ${ }^{16}$ requires most employed persons to purchase an annuity which is paid to them after they have reached a qualifying age but only if they substantially retire from employment. The annuity is withheld from those older persons who continue to work. The specific form of the rule is that the annuity will not be paid to those whose earnings from employment exceed a specified number of dollars in a year. The law essentially prescribes a lifetime distribution of expenditures of earnings which is different from the distribution that would be preferred by some people. In different words, the law requires the deferment of consumption from earlier to later years of life. On equity grounds, it is questionable whether deferred income earned by rendering services when young should be denied older persons, so long as they continue to work. It can be sensibly argued that it is theirs by right and they should have it. But set this aside. It is surely correct that the present policy creates an incentive for retirement. Some older persons who would be otherwise disposed to continue to work are induced by the law to stop. If they do not stop, they may not have their annuity benefit. The output of the whole economy is, therefore, less by some magnitude; the smaller the output, the larger the quantity of poverty. And the policy precisely induces older people to earn less. The act generates poverty among the aged.

\footnotetext{
${ }^{10} 49$ Stat. 620 (1935), as amended (codified in scattered sections of 42 U.S.C.)).
} 
5. The regulation of some industries by government inhibits entry into these industries. Artful defenses for these policies are constructed in terms of the public interest, but it is clear that the result and sometimes the object of this exercise is to cartelize the relevant industry. The consequence is that some industries are too small and, therefore, that others are too large, in terms of some optimal allocation of resources among industries. The final effect is that output is less and poverty deeper.

6. Public monetary and fiscal policy had generated almost continuous inflation; that is to say, the general level of prices has almost continuously risen. Such a policy disadvantages fixed-income earners, among them receivers of annuity payments and holders of relatively risk-free securities. Such persons are, of course, especially the aged, and a policy of inflation tends to impoverish them.

7. A policy of equal-pay-for-equal-work for men and women is common among the states. Such a policy makes it less attractive for firms to employ women rather than men. It is a policy that favors men over women by assuring men that women will offer them less competition for employment and that damages women by driving them to unemployment or to second-best employment options. Women who are heads of families are made worse off by it.

8. The incidence of poverty rises with rising numbers of children in the family. Whatever encourages parents to produce more offspring will produce more poverty. While the magnitude of the effect may not be large, the policy of granting exemption from income for children when computing tax liability will tend in that direction.

9. The amount of poverty in a community is a function of the quantity of goods and services it produces in some time period and of the distribution of income. Given the distribution, the more that is produced the less poverty there will be. Whatever creates production disincentives will increase the number of the poor. A system which distributes rewards in proportion to knowledge, effort, and skill will tend to cause output to be larger; some other system will diminish the quantity of knowledge assimilated, effort exerted, and skill learned and will have adverse effects upon output. Some welfare payments to the poor and some unemployment benefits, by providing substitute "earnings" for those that would be yielded by work, diminish incentives to work and cause output to be smaller. The welfare payments and benefits need not be as large as prospective earnings from work to have these disincentive effects, since leisure is a preferred good that is incorporated in the calculus of decision. Unemployment benefits received under some insurance system are especially vulnerable in this respect since the failure to work is precisely a condition for their payment. They are significantly different from savings from prior earnings by individuals to "tide them over" periods of unemployment. These are assets which the individual has whether he works or not; in an insurance scheme, he is given the benefits only if he does not work. Thus the policy encourages less work by making leisure less costly. 
10. The earnings of skilled workers are higher than those of the unskilled. These higher earnings are, in part, payment for the investment of time, effort and money in the acquisition of the skill. Given the cost of acquiring skill, the larger is the difference in earnings at the two levels of skill, the larger is the incentive to make the investment, and the larger is the number who make this investment. Public policy makes welfare payments to the poor. We may think of the whole receipts of the skilled as being the wage payments made to them for the services they render; they receive no welfare payments because their wage earnings are high enough to disqualify them. The whole receipts of the unskilled, however, are the sum of their lower wage earnings and their welfare receipts. The welfare payments for which only the poor (say the unskilled) qualify serve to diminish the size of the difference between the earnings of the skilled and the unskilled and reduce the incentive to invest in the learning of skill. In a sense, the system pays people to refrain from investing in themselves. The mean level of skill in the whole population is less and, therefore, so is the output of the economy. The policy has povertygenerating effects.

Ir. Some of the poor are in declining regions. They may live in the vicinity of cutover forests or exhausted coal mines, for example. The population of these regions may rise while opportunity in them falls; or opportunity may rise at a slower rate than does population. There are too many people there, from the vantage point of income earned. If outmigration from such regions is large and rapid enough, those remaining need not endure poverty and those who go are more productive and have higher earnings than if they had stayed. If prospective outmigrants are induced to stay, the condition of regional poverty is reinforced and the country as a whole is made poorer. There are, of course, public policies to make "welfare" payments to residents of these distressed regions which they receive only if they remain there. This tends to perpetuate poverty by diminishing the magnitude of corrective action that goes to its root cause.

12. A significant fraction of poor families are those without a male head. It is not clear that the law has worked well to compel fathers to provide for the care and maintenance of their children, when they are disposed to abandon them.

This is not, of course, a complete catalogue. It is, however, a sample that is sufficiently large to suggest that some not insignificant fraction of the poverty which is experienced in this country is produced by governments executing policies whose consequences have perhaps not been fully foreseen. At least marginal behavior is responsive to incentives, both positive and negative. People will attempt to capture gains and to escape costs. Policy-makers seem always to ignore the fact that policies have consequences, or they forecast the future falsely because some other object than utility-maximization is assumed to explain behavior.

The war on poverty which, it is said, is now being waged in the United States 
is a melange authorized by the Economic Opportunity Act of $1964^{17}$ and administered by the Office of Economic Opportunity. For the most part, the Office of Economic Opportunity acts as though it were a granting endowment or a contractor rather than executing programs itself. The most important programs, measured by cost, are Community Action, Job Corps, Neighborhood Youth Corps, Work Experience, College Work Study, Small Business and Rural Loans, and Literacy.

The condition of being poor is the same as receiving relatively low income. If one reviews the circumstances that cause income to be low, it is clear that there are many causes that are left apparently untouched by the Office of Economic Opportunity. Who are the low-income receivers? They include the sick, the disabled and infirm, the aged, the young, families abandoned by fathers, the selfemployed in declining industries, those who suffer racial disabilities, those without skill, and families with many children.

There are two roads to raising the incomes of people-make transfer payments to them, as when they receive "gifts"; and cause them to earn more, either by working more or by becoming more productive. Becoming more productive can be achieved either by removing to a more productive occupation (given skills possessed) or by acquiring additional skills.

There are some among the poor whose condition cannot be improved greatly except by making transfer payments to them. It cannot be said with certainty that the war on poverty excludes these classes because it is not clear what the "community action programs" are and some of them could, possibly, make payments in kind to members of these classes. Other public programs, not encompassed by the Economic Opportunity Act, do make payments to certain of them.

But it seems in general to be true that many of the causes of low income lie outside the programs authorized by the act or are touched by them only tangentially. The war on poverty is not essentially a health program to reduce the incidence of morbidity or the mean duration of illness; it does not offer incentives for people to leave declining occupations, industries, and regions; it does not attempt to prolong the duration of working life; it does very little to reduce family size, family abandonment, or the disabilities that attach to race. Indeed, in some respects, the act fosters poverty. When the act provides for subsidies to farmers (low-interest rural loans) it reduces the incentive to leave agriculture; when it provides housing, sanitation, and child care services to migrant workers, it reduces the incentive to take regular employment (and incidentally cheapens the cost of labor to employers of migrant labor); when it offers services to young children, it diminishes their cost and reduces the incentive to parents to have more care.

A large part of the funds appropriated for the war on poverty are said to be

\footnotetext{
${ }^{17} 78$ Stat. 508,42 U.S.C. $\$ \$ 2701-981$ (1964).
} 
devoted to the promotion of education of young people. The literature of the OEO offers these programmatic descriptions: ${ }^{18}$

The Job Corps: A program of remedial education and job training for young men and women.

The Neighborhood Youth Corps: . . provides full- or part-time work experience and training for youths... enabling them to stay in or return to school, or increase their employability.

College Work Study: . . provides part-time employment of college and university students from low-income families.

Because this cohort of programs is quantitatively so important, it is deserving of special critical attention. These programs seem to be intended to treat the problems of school dropouts, actual or prospective, by subsidizing continued schooling or re-entry into school of those who have already withdrawn, and we shall discuss these programs in this light. ${ }^{19}$

Students enrolled in school are engaged in one or another of two distinct economic activities, or some combination of them in variant proportions. They may be consuming; that is to say, deriving utility (as a first approximation, satisfaction) from the act of learning. And they may be investing; that is to say, learning some "skill," either general or specific, that will cause their output (and earnings) to be higher in the future than they would then be, if they had not been enrolled in school. Both the consumption and the investment gains of schooling are acquired at what economists call an opportunity cost. Something is given up or sacrificed in exchange for them. The opportunity cost of schooling is the output (earnings) foregone. If the student had not been enrolled at school, he could, in principle, have let his services out to hire and they could have been used to produce goods and services. This would have produced income for him. A student loses this income and the community loses the output he would have produced. If the student had dropped out of school and worked instead, he could have converted the income he would then have earned to goods and services produced by others. These would have produced utility for him.

With respect to the current consumption calculus, every student, by choosing to study rather than work, decides, at the least implicitly, that the bundle of utilities yielded to him by consuming education as well as other things is larger than some alternative bundle which included the consumption of less (including zero) educa-

\footnotetext{
${ }^{18}$ I Office of Economic Opportunity, Congressional Presentation 13, 23, 29 (1965).

${ }^{10}$ Jobs Corps and Work Experience on-the-job training will be referred to, for convenience, as "schooling"; this is consistent with their announced object. Subsidizing the continued enrollment of students (prospective dropouts) in formal schools is the same in principle as subsidizing the re-enrollment of dropouts. They will be collapsed, for simplicity of exposition, to the single cases of subsidizing the re-enrollment of those already withdrawn. Some of the discussion that follows was suggested by Eugene Smolensky in "Investment in the Education of the Poor: A Pessimistic Report," a paper read at the meetings of the American Economic Association in December 1965. He is not responsible for what follows.
} 
tion and more of other things. With respect to the lifetime individual consumption calculus, every student decides that the lifetime bundle of utilities he will consume is sufficiently larger, if he enrolls at school than if he does not, to warrant his sacrificing some utility in the present, by consuming less, for the sake of having more of it in the future. The solution to this problem is complicated by the influence of a time preference variable. There is less uncertainty in the present than in the future and the quantum of uncertainty is a function of time, so that the farther one peers into the future, the more uncertainly is it seen. Partly for this reason, and for others as well, the present is preferred to the future. If one is asked, "Shall I give you $\$ 100$ now or $\$ 200 x$ years from now or $\$ 3002 x$ years from now?," the response will vary among individuals, some of whom have a stronger preference for the present over the future than others and, correspondingly, have a stronger preference than others for the near future over the distant future. All individual time preferences are aggregated by the market and they are expressed by a market rate of discount.

The payment of a subsistence scholarship to school dropouts who re-enroll in school changes the magnitudes of the variables that would otherwise govern for each individual the choice for which he opts between the two alternatives: enroll in school or work. The subsistence payments diminish the opportunity costs of schooling and the extent to which they are diminished depends upon the size of those payments. If, for illustration, they are as large as his earnings would have been, if he had worked, they reduce his opportunity cost to zero. He would then be permitted to consume in the present as much of goods and services other than education as he would have consumed if he had sold his labor services during the hours of school and, as well, to secure the consumption utilities of schooling and the enlarged future income that the schooling will produce for him. He has the best of all possible worlds. If the subsistence payments are less than this, but still some positive number, the magnitude of the effect will be less, but the direction will be the same. Each additional increment in the size of the subsistence payment above zero can be expected to cause some additional persons to withdraw from the labor market and to enroll in school.

Does a policy of granting subsistence scholarships to induce school dropouts to re-enroll in school serve the social purpose? Every individual makes a large number of sequential decisions that will serve his own purposes in selecting among alternative bundles of consumption goods confronting him and in distributing his consumption over his lifetime. His behavior is responsive to a set of incentives, which may be positive or negative, and which are in the nature of signals to him. One set of these signals takes the form of market prices. If some good becomes more costly to make, or if it requires a resource for its making which has become more scarce, its price will rise and this is a signal to some to forego its consumption. For if the decision were made to consume it, more of other things that could be purchased for 
the same amount of money would be foregone. Thus, the signaling system suggests that what becomes more costly or scarce should be economized more.

In the same way, market prices signal what a student at the margin of deciding whether to continue in school or drop out should do. The cost of continued schooling for a high school student is something like the product of the price paid for the services of relatively unskilled labor and the magnitude of the probability that, if the student should offer his services as an unskilled worker, he will be employed at all in that capacity.

When the wages of unskilled labor are high, relative to those of skilled labor, and when the rate of unemployment among young people is low, the cost of continued schooling is relatively high and some young people are signaled to drop out. Relatively high unskilled wages is the same as relatively low skilled-worker wages; relatively low skilled-worker wages means that the payoff to the acquisition of skills (as from schooling) is low. Thus when the cost of schooling is high, the expected gain from schooling is low. The signal on the gain side of the ledger also says "drop out." Oppositely, when the wages of unskilled labor are a smaller fraction of those of skilled labor and when the rate of unemployment among the young is high, the cost of schooling is relatively low and the signal is "continue in school." This is reinforced by the signal with respect to the gain component of the calculus; skilled-worker wages are now relatively high; it pays some to stay in school who would otherwise have withdrawn. These signals are not randomly generated. They express, through market aggregation processes, the social will.

We can assume, a priori, that no community desires that all of its members spend all of their days for the whole of their lives at school in every generation, for if it did, in that society nothing would be produced and, therefore, nothing would be consumed other than the commodity, educational services. Similarly, we would not expect to find any communities that were unwilling in any circumstances to have any of its members at school for any days at all, for such a community would be willing to sacrifice nothing in the present for the sake of more in the future, however small the current sacrifice and however large the future gain from the formation of human capital. All communities can be expected to fall somewhere on the continuum between the polar extremes. This is equivalent to saying that all communities desire that some fraction of its population be enrolled at school. The fraction that corresponds to the social will can be called the optimal fraction. The optimal fraction will vary from time to time in any society. The signaling system that is the instrument for causing the optimal fraction to occur in the world is the cost of continued schooling and changes in that cost over time and the payoff to continued schooling and changes in that payoff over time.

We observe that the wages of unskilled workers are relatively high in good years and relatively low in bad years. We observe also that the rate of unemployment among 
the young is low in good years and high in bad years. We would expect, therefore, that there are more school dropouts in good years and fewer dropouts in bad years and this is exactly consistent with what the society has signaled, through the market, that it desires to occur. If, now, in the good years of large-scale withdrawal from school, public policy pays dropouts to return to school, it frustrates the achievement of the optimal solution to the problem of finding that fraction of the population to be enrolled in school which the community desires. It causes the community to consume more educational services currently than it desires and less of other things; and it causes the community to sacrifice more in the present than it desires so that it will have more in the future than it desires, given the cost.

It may be argued that the social purpose is being given utterance through politically collectivized processes of modifying market signals but this is defensible only if the market does not function efficiently to express the whole of this purpose in the first instance. Nowhere in the literature that generated the scholarships-fordropouts policy is such a defense to be seen. What seems more likely is that the public policy-makers operated from simplistic and naïve premises: education is a good thing; ergo, the more of it the better. It may be, of course, that a dropout was misinformed; he believed that unskilled-worker wages were higher than he later found them to be, or skilled-worker wages lower, or he believed he would be employed and was not. But experience teaches and, having once assimilated the information that he was mistaken, one would expect him to return to school. If one wants to cheapen these costs, then it would seem appropriate to establish some instrument to disseminate information that would diminish the probability of error. But this is immensely different in its effects from subsidizing re-enrollment. The production of information tends to produce phenomena that coincide with community goals; re-enrollment subsidies tend to obstruct the occurrence of this coincidence.

Antipoverty policy perhaps has its genesis in estimates that it can be turned to political capital because the lower-income classes are finding new and more aggressive instruments of expression and in feelings of guilt and compassion of the middle classes. The object of this critical exercise has been to suggest to the latter that Pavlovian responses to word signals is a poor substitute for the use of rational intelligence. The words "war on poverty" are no exception to this rule. 